Olivier Mimoz

Philippe Montravers José-Artur Paiva

\section{Continuous administration of linezolid in pneumonia: what is the level of proof?}

Received: 16 November 2014

Accepted: 18 November 2014

Published online: 26 November 2014

(C) Springer-Verlag Berlin Heidelberg and ESICM 2014

O. Mimoz (®)

CHU de Poitiers, Service d'Anesthésie Réanimation, Université de Poitiers, INSERM U1070, Poitiers, France

e-mail: o.mimoz@chu-poitiers.fr; olivier.mimoz@chu-poitiers.fr

\section{P. Montravers}

Department of Anesthesiology and Surgical Intensive Care, Bichat-Claude Bernard University Hospital Center,

Paris Diderot University, Sorbonne Paris-Cité and AP-HP, 46 Rue Henri-Huchard, 75018 Paris, France

e-mail: philippe.montravers@bch.aphp.fr

\section{J.-A. Paiva}

Emergency and Intensive Care Medicine Department, Centro Hospitalar Sao Joao, Faculty of Medicine,

University of Porto, Porto, Portugal

e-mail: jarturpaiva@gmail.com

Linezolid, the first available oxazolidinone derivative, has been shown to be an interesting alternative to glycopeptides against resistant gram-positive strains [1]. It distributes well into the lung, with mean percentage penetration in epithelial lining fluid of approximately $100 \%$, indicating that serum concentrations adequately predict antibiotic concentrations at the target site for extracellular respiratory tract pathogens [1]. Linezolid is a time-dependent antimicrobial agent with a reduced postantibiotic effect. The best pharmacokinetic/pharmacodynamic (PK/PD) parameters to define its activity are time with serum concentrations higher than the minimum inhibitory concentration $(T>$ MIC) and area under the serum concentration-time curve/minimum inhibitory concentration (AUC/MIC) ratio [1]. Linezolid is mainly a bacteriostatic antimicrobial agent with $T>$ MIC of at least $40 \%$ being predictive of its efficacy. This objective can be easily achieved for pathogens with MICs of $2-4 \mathrm{mg} / \mathrm{l}$ by administration of standard dosing $(600 \mathrm{mg}$ intravenously twice a day) in healthy volunteers, suggesting that continuous infusion, the best antimicrobial administration modality for most time-dependent antibiotics as it prolongs effective serum concentrations, may not be essential [1].

During the initial phase of septic shock, however, alterations in pharmacokinetic parameters, mostly due to an increase in the volume of drug distribution and/or drug clearance, are frequently observed [2]. These modifications vary from one patient to another and in a single patient from one day to another [2]. They may lead to suboptimal serum and tissue concentrations when drugs are given at the dosage studied in healthy volunteers or in less seriously ill patients. Moreover, critically ill septic patients should be considered as immunosuppressed, and antimicrobials with bactericidal activity may be more effective than those exhibiting only bacteriostatic activity [3]. In an in vivo model of endocarditis, linezolid demonstrated bactericidal activity when $T>$ MIC was maintained for $>75 \%$ of the dosing interval [4]. On the basis of these considerations, achieving $T>$ MIC close to $100 \%$ is probably the key to obtaining the highest success rate with linezolid in ICU patients.

Recently, Zoller et al. [5] showed that there was a high variability of linezolid serum concentrations after standard dosing in 30 critically ill infected patients with a median body mass index of $26 \mathrm{~kg} / \mathrm{m}^{2}$ (range $16-35 \mathrm{~kg}$ / $\mathrm{m}^{2}$ ), mostly with lung infections. Optimal pharmacodynamic exposure over $24 \mathrm{~h}$, with $\mathrm{AUC}_{0-24 \mathrm{~h}}$ values between 200 and $400 \mathrm{mg} \mathrm{h} / \mathrm{l}$ and with $C_{\min }$ values between 2 and $10 \mathrm{mg} / \mathrm{l}$, could be observed for only 30 and $43 \%$ of the patients, respectively. Regarding these $\mathrm{AUC}_{0-24 \mathrm{~h}}$ and $C_{\min }$ values, 63 and $50 \%$ of the patients, respectively, had linezolid concentrations below the lower limit of the corresponding target concentration range and only $7 \%$ 
were above the target concentration range. Moreover, only $17 \%$ of the patients continuously attained optimal $C_{\min }$ values over the 4 days of the study period. Therefore, there was a high variability of linezolid $\mathrm{AUC}_{0-24 \mathrm{~h}}$ and $C_{\min }$ values, with $C_{\min }$ values differing more than 100 -fold between the different patients and more than 30 -fold within single patients. These data are in line with other studies observing very low, usually insufficient $\mathrm{AUC}_{0-24 \mathrm{~h}}$ or $C_{\min }$ linezolid values [6-8] and also in line with papers showing $C_{\text {min }}$ values differing more than 50-fold between different patients [8,9].

This PK/PD conundrum is particularly difficult in obese patients. Despite the worldwide debate related to the increase in the incidence of obesity, few data are available on ventilator-associated pneumonia in morbidly obese patients. In a meta-analysis comprising a total of 62,045 critically ill subjects, obesity was significantly associated with prolonged duration of mechanical ventilation and ICU length of stay, suggesting an increased risk in this population [10]. In a recent analysis gathering more than 4 million morbidly obese hospitalized patients, Kumar et al. [11] reported 119,000 (2.9\%) requiring mechanical ventilation. Interestingly, pneumonia as a cause of mechanical ventilation was reported in proportions similar to those in nonobese patients in this study. In the Nationwide Inpatient Sample database, Masoomi et al. [12] analyzed more than 300,000 patients who underwent bariatric surgery during a 3-year period and reported an incidence of $1.35 \%$ postoperative acute respiratory failure. Similarly, Gupta et al. [13] reported incidences of postoperative pneumonia and respiratory failure after bariatric surgery as low as $0.6 \%$ for both diagnoses. Overall, these reports suggest that the pulmonary risk of morbidly obese patients is close, if not similar, to that of nonobese patients.

Only limited pharmacological data are available in morbidly obese patients in the ICU setting, especially concerning the use of antiinfective agents. The appropriate antibiotic doses in these specific cases have not been clearly defined and are largely based on extrapolations from nonobese patients or plasma assays when available. The majority of the publications focused on plasma concentrations of $\beta$-lactams. However, prescribing physicians should always remember that diffusion of antibiotics in anatomical spaces cannot be easily predicted and is impossible to monitor. These patients are at risk of both under- and over-dosing, as recently reported in a study of serum $\beta$-lactam concentrations, where
Table 1 Reasons to use linezolid by continuous infusion

Difficult-to-treat infection plus at least one of these conditions Septic shock

Large volume resuscitation

High cardiac output

Measured creatinine clearance $>160 \mathrm{ml} / \mathrm{min}$

Immunosuppressed patients

Body mass index $>25 \mathrm{~kg} / \mathrm{m}^{2}$

Staphylococcus aureus with MIC to linezolid $>2 \mu \mathrm{g} / \mathrm{ml}$

insufficient serum concentrations were observed in $32 \%$ of cases and excessive concentrations in $25 \%$ of cases [14]. In addition, some recent data suggest that in patients undergoing scheduled surgery, tissue distribution is altered, with a $30 \%$ decreased penetration ratio compared to nonobese patients [15].

In an article recently published in Intensive Care Medicine, De Pascale et al. [16] add evidence in favor of using linezolid by continuous infusion, especially in critically ill obese patients. This study shows that intermittent administration in obese critically ill patients with ventilator-associated pneumonia is associated with suboptimal plasma concentrations and that continuous infusion administration is able to safely improve the linezolid pharmacokinetic profile. In this study, critically ill status and obesity did not strongly affect pulmonary distribution but continuous infusion provided a higher alveolar penetration ratio. Nevertheless, even using continuous infusion, the usual dose may still be inadequate for the management of bacteria with high MIC for linezolid.

The dose and dose interval are paramount decisions to achieve antibiotic adequacy, especially in critically ill obese patients. Underexposure at the infection site may lead to reduced efficacy, higher mortality and development of antimicrobial resistance. On the other hand, overexposure may lead to drug-related toxicity. The high variability of linezolid serum levels between patients and within single patients over the course of time leads to the conclusion that therapeutic drug monitoring would be beneficial for its correct use in critically ill patients. Individual antimicrobial dosing by aid of therapeutic drug monitoring would clearly be the best solution, but until linezolid quantification methods are easily available perhaps linezolid should be prescribed by continuous infusion in difficult-to-treat infections and in patients such as those described in Table 1. 


\section{References}

1. Dryden MS (2011) Linezolid

pharmacokinetics and

pharmacodynamics in clinical treatment. J Antimicrob Chemother 66(Suppl 4):iv7-iv15

2. Roberts JA, Abdul-Aziz MH, Lipman J, Mouton JW, Vinks AA, Felton TW, Hope WW, Farkas A, Neely MN, Schentag JJ, Drusano G, Frey OR, Theuretzbacher U, Kuti JL, International Society of Anti-Infective Pharmacology and the Pharmacokinetics and Pharmacodynamics Study Group of the European Society of Clinical Microbiology and Infectious Diseases (2014) Individualised antibiotic dosing for patients who are critically ill: challenges and potential solutions. Lancet Infect Dis 14:498-509

3. Pangault C, Le Tulzo Y, Tattevin P, Guilloux V, Bescher N, Drénou B (2006) Down-modulation of granulocyte macrophage-colony stimulating factor receptor on monocytes during human septic shock. Crit Care Med 34:1193-1201

4. Dailey CF, Dileto-Fang CL, Buchanan LV, Oramas-Shirey MP, Batts DH, Ford CW, Gibson JK (2001) Efficacy of linezolid in treatment of experimental endocarditis caused by methicillinresistant Staphylococcus aureus. Antimicrob Agents Chemother 45:2304-2308

5. Zoller M, Maier B, Hornuss C, Neugebauer C, Döbbeler G, Nagel D, Holdt LM, Bruegel M, Weig T, Grabein B, Frey L, Teupser D, Vogeser M, Zander J (2014) Variability of linezolid concentrations after standard dosing in critically ill patients: a prospective observational study. Crit Care 18:R148
6. Morata L, Cuesta M, Rojas JF, Rodriguez S, Brunet M, Casals G, Cobos N, Hernandez C, Martinez JA, Mensa J, Soriano A (2013) Risk factors for a low linezolid trough plasma concentration in acute infections. Antimicrob Agents Chemother 57:1913-1917

7. Adembri C, Fallani S, Cassetta MI, Arrigucci S, Ottaviano A, Pecile P, Mazzei T, De Gaudio R, Novelli A (2008) Linezolid pharmacokinetic/ pharmacodynamic profile in critically ill septic patients: intermittent versus continuous infusion. Int J Antimicrob Agents 31:122-129

8. Swoboda S, Ober MC, Lichtenstern C, Saleh S, Schwenger V, Sonntag HG, Haefeli WE, Hempel G, Hoppe-Tichy T, Weigand MA (2010) Pharmacokinetics of linezolid in septic patients with and without extended dialysis. Eur J Clin Pharmacol 66:291-298

9. Cattaneo D, Orlando G, Cozzi V, Cordier L, Baldelli S, Merli S, Fucile S, Gulisano C, Rizzardini G, Clementi E (2013) Linezolid plasma concentrations and occurrence of drug-related haematological toxicity in patients with Gram-positive infections. Int $\mathbf{J}$ Antimicrob Agents 41:586-589

10. Akinnusi ME, Pineda LA, El Solh AA (2008) Effect of obesity on intensive care morbidity and mortality: a metaanalysis. Crit Care Med 36:151-158

11. Kumar G, Majumdar T, Jacobs ER, Danesh V, Dagar G, Deshmukh A, Taneja A, Nanchal R (2013) Outcomes of morbidly obese patients receiving invasive mechanical ventilation: a nationwide analysis. Chest 144:48-54
12. Masoomi H, Reavis KM, Smith BR, Kim H, Stamos MJ, Nguyen NT (2013) Risk factors for acute respiratory failure in bariatric surgery: data from the Nationwide Inpatient Sample, 2006-2008. Surg Obes Relat Dis 9:277-281

13. Gupta PK, Gupta H, Kaushik M, Fang X, Miller WJ, Morrow LE, ArmourForse R (2012) Predictors of pulmonary complications after bariatric surgery. Surg Obes Relat Dis 8:574-581

14. Hites M, Taccone FS, Wolff F, Cotton F, Beumier M, De Backer D, Roisin S, Lorent S, Surin R, Seyler L, Vincent JL, Jacobs F (2013) Case-control study of drug monitoring of beta-lactams in obese critically ill patients. Antimicrob Agents Chemother 57:708-715

15. Brill MJ, Houwink AP, Schmidt S, Van Dongen EP, Hazebroek EJ, van Ramshorst B, Deneer VH, Mouton JW, Knibbe CA (2014) Reduced subcutaneous tissue distribution of cefazolin in morbidly obese versus nonobese patients determined using clinical microdialysis. J Antimicrob Chemother 69:715-723

16. De Pascale G, Fortuna S, Tumbarello M, Cutuli SL, Vallecoccia M, Spanu T, Bello G, Montini L, Pennisi MA, Navarra P, Antonelli M (2014) Linezolid plasma and intrapulmonary concentrations in critically ill obese patients with ventilator-associated pneumonia: intermittent vs continuous administration. Intensive Care Med. doi:10.1007/s00134-014-3550-y 